\section{How mental illness is portrayed in children's}

\section{television}

\author{
A prospective study \\ CLAIRE WILSON, RAYMOND NAIRN, JOHN COVERDALE \\ and AROHA PANAPA
}

\begin{abstract}
Background There are no published studies concerning the depiction of mental illness in children's television programmes.
\end{abstract}

\begin{abstract}
Aims To determine whether mental illness was depicted in children's television.

Method Sample of one complete week of children's television (57 hours, 50 minutes; 128 series episodes: 69 cartoon animations, 12 non-cartoon animations, 47 real life) provided for children under the age of 10 years. Disclosure analysis of portrayals of mental illness through repeated viewings identified patterns in the use of linguistic, semiotic and rhetorical resources.
\end{abstract}

Results Of the 128 episodes, 59 (46\%) contained one or more references to mental illness, predominantly in cartoons ( $n=47,80 \%$ ) compared with other episode types ( $\chi^{2}=17.1$, d.f. $=2, P<0.05$ ). Commonly occurring terms such as 'crazy' ( $n=28)$,'mad' ( $n=19$ ) and 'losing your mind' $(n=13)$ were employed to denote loss of control. The six consistently mentally ill characters were almost entirely devoid of admirable attributes.

\section{Conclusion Young viewers are being} socialised into stigmatising conceptions of mental illness.

Declaration of interest Funding was provided by a Faculty of Medicine and Health Science grant.
The effects of television viewing on children and the portrayals of mental illness in the media have both been objects of sustained investigation (Centrewall, 1992; Philo, 1996; Diefenbach, 1997). In both areas there has been extensive discussion of the social implications of the findings yet we could find no published work that brings these two fields together by examining how mental illness is portrayed in television programmes for children. Analyses of media depictions of mental illness have been concerned to describe how disorders are portrayed, how the portrayals are deployed by the producers, and how the portrayals relate to the negative attitudes observed toward mental illness (Wahl, 1992). Researchers examining various media in different countries and using differing analyses have consistently reported that depictions of mental illness are overwhelmingly negative (Signorielli, 1989; Hyler et al, 1991; Philo et al, 1993; Wahl, 1995). There is a similar consistency in the negative stereotypes of and attitudes toward mental illness (Brockington et al, 1993; Wolff et al, 1996) although demonstrations of the links between media depictions and these attitudes are rare (Wahl, 1992; Philo, 1996). Despite this, the evidence has been considered strong enough for mental health professionals to suggest changes that included involving psychiatrists more in production of media accounts (Matas et al, 1985), promulgating awards for excellence in reporting and codes of practice for the media (Philo et al, 1994), and developing a closer liaison between mental health services and media (Mayer \& Barry, 1992). In light of such concerns, and the lack of research concerning media depictions of mental illness in children's television, we sought answers to two questions in examining our sample of children's television. Is mental illness depicted? And, if it is depicted, what patterns can be identified in the portrayals and their use?

\section{Theoretical background}

Siegal's (1991) studies of children's cognitive development showed that children, like adults, create their understandings of their world out of the talk about, and depictions of that world to which they are exposed. Children demonstrate such understandings when their talk about television is analysed (Buckingham, 1991). The efficacy of such learning is established in studies of cigarette advertising that show evidence of children's familiarity with signification and the use of symbols (Aitken et al, 1987). These findings are consistent with Halliday's (1978) view that children learn languages, social relationships and ways of structuring the world through listening to and participating in talk about their world.

Central to recent studies of portrayals of mental illness has been a concern with the vocabulary of stigmatisation, recognising that such stigmatising terms arose out of widely employed understandings of mental disorders that could be deployed for rhetorical purposes. Philo et al (1993, see Appendix 1) listed 165 terms about mental illness from their adult, UK media sample, the overwhelming majority being pejorative. The list included a considerable number of terms, such as: barking mad, crackers, crazy, dotty, headcase, loony, nuts, off his rocker and screw loose, often used in jokes and for other humorous purposes. Wahl (1995), discussing the relationship between words and humour in US media, listed stigmatising terms used in advertising, jokes and media including: crazy, sick, nut, wacko, wierdo, screwy, fruitcakes, kooks, cuckoo-birds and loonies. Even if children's understanding of terms related to mental illness should vary from that of adults, an acquaintance with these terms exposes them to the language and images that are a part of adult vocabulary. If children are to grow into adults who sustain and reproduce the stigma of mental illness (as they have been doing over many generations) they must be conversant with the manner in which these resources are deployed in their society.

For this study we used a form of discourse analysis which seeks to identify the patterned use of linguistic and rhetorical resources in portrayals of mental illness in samples of published or broadcast material. Models for our study are provided by studies of race relations (Nairn \& McCreanor, 1991; McCreanor, 1997), 
gender (Holloway, 1989) and scientific talk (Mulkay, 1985). Our analyses are undertaken within a framework created by the production practices (Fairclough, 1993) of the television medium. For example, in entertainment we are engaged with stories and narratives about characters whose nature and motivation are created by their appearance, their words, and their actions as well as through the responses of other characters to them (Butler, 1994). Further, the impact of these elements can be heightened or moderated by technical aspects of the production (Wilson et al, 1999a). In this study we include these technical aspects among the discursive resources contributing to the broadcast depiction. With respect to mental illness we would expect children's television to rely upon a simplified subset of the discursive resources identified in adult materials (Wilson et al, 1999b).

\section{METHOD}

Correspondence with broadcasters at Television New Zealand identified two of the four, free of charge television channels as providing sessions aimed at children under the age of 10 years. These two television channels featured early morning (6.309 a.m.) and mid-afternoon (3.00-4.30 p.m.) time-slots for children's programmes. The programmes achieve broad demographic coverage and viewership.

The sample analysed in this study was one complete week of children's television from both these channels. This study included 46 different children's programmes. Of these $29(60 \%)$ were produced in the USA, including $81.5 \%$ ( 22 of 27 titles) of the cartoon animations.

These 46 children's programmes involved 128 series episodes. An episode was defined by the daily programme timeslot and usually comprised a full length story. However, within one episode, two or three distinct short stories could be run separated by advertisements. These episodes were unequally dispersed as 69 cartoon animations $(54 \%$, duration 33 hours 25 minutes), 12 non-cartoon animations comprising three-dimensional, computer and model animations $(9 \%$, duration 1 hour 20 minutes) and 47 real life episodes those that involved living people although they often incorporated some puppetry or virtual computer images $(37 \%$, duration
23 hours 5 minutes). The total duration of the sample was 57 hours, 50 minutes.

Initial systematic viewing of the study sample using the criteria of Wahl \& Roth (1982) identified occasions on which mental illness was talked about, instantiated and incorporated into the story. These mental illness references were defined by the use of vocabulary, as well as behaviour and situations within episodes. In analysing mental illness references attention was paid to the relevant discourses and semiotic systems. Critical repeated viewings of the relevant material followed to break down the components of the references and to identify common elements and patterns. Evaluations of ratings were checked and discussed by the authors in order to achieve agreement. The proportions of depictions in cartoon, non-cartoon animations and real-life episodes were tested using the $\chi^{2}$ method.

Characters were defined as mentally ill when they were consistently referred to by other characters as having a mental illness. While there were a small number of such characters, there was also a quite widespread use of mental illness terms for evaluating or describing actions. A word, 'crazy' for example, might be used to evaluate a particular behaviour rather than suggest a mental illness or disorder, so we made no attempt to provide a formal psychiatric categorisation on the basis of actions.

\section{RESULTS}

Of the 128 episodes (69 cartoon animations, 12 non-cartoon animations, 47 real life), $59(46.1 \%)$ contained one or more references to mental illness. Of the 59 episodes containing references, the overwhelming majority occurred within cartoons $(n=47,79.7 \%)$. The remaining 12 episodes $(20.3 \%)$ were real life. These differences between the rates of occurrence across the three episode categories were significant $\left(\chi^{2}=17.1\right.$, d.f. $\left.=2, P<0.05\right)$.

In the 59 episodes containing one or more references to mental illness there was a total of 159 references. The bulk of these references were in cartoon animations $(133,83.5 \%)$ with the remainder (26, $16.4 \%$ ) in real life episodes. The difference in rates across the three episode categories was significant $\left(\chi^{2}=59.0\right.$, d.f. $\left.=2, P<0.05\right)$. As there were no mental illness references in the non-cartoon animations these items are not referred to in what follows.

\section{Vocabulary}

The most common terms for mental illness in children's television were 'crazy' $(n=28)$, 'mad' $(n=19)$ and 'losing your mind' ( $n=13)$. Crazy was employed widely both to judge actions, ideas, characters and objects as unreasonable, irrational, illogical or unacceptable, and to connote fun, wildness, spontaneity, passion and unpredictability. Like crazy, mad was used ambiguously; some uses favoured mad as crazy while other uses were weighted to mad as angry, although both usages implied a loss of control. Other commonly employed terms included 'nuts' $(n=10)$, 'driven bananas' $(n=10)$, 'twisted, deranged' or 'disturbed' $(n=10)$, 'wacko' or 'cuckoo' $(n=9)$, 'loony, lunatic' or 'loon' $(n=7)$, 'insane' $(n=6)$, and 'freak' $(n=6)$. Stereotypic signs for insanity such as motions to the head and rolling eyes $(n=6)$ also occurred.

Language in these programmes was typically colloquial and, in cartoons, concurrent with scenes or actions that were unconstrained by any natural law. A sense of this can be conveyed by the song that introduces Tiny Toon Adventures, an animated cartoon produced by Steven Spielberg for Warner Brothers. It begins with a rainbow coloured target with a blank centre in which Babs and Buster Bunny appear. The words are: "We're tiny, we're toony, we're all a little loony and in this cartoony we're invading your TV". At the "all a little loony" the screen is filled with cartoon characters who then pour out of the front of the pictured television in a purposeful manner. The song closes with the toons repeating the first line standing beneath an entrance arch at their 'looniversity' before disappearing into the blank centre of the target for; "Its Tiny Toon Adventures come and join the fun". Babs and Buster Bunny then reappear for the final line; "And now our song is done". Within the song viewers are introduced to 10 named characters, concluding with; "and Go-Go is insane", whereupon that character hits himself on the head with a mallet converting to five laughing Go-Go's.

Many of the references to mental illness were judgements about a character's actions in a situation rather than the character's nature or mental state. For example, there was a set of evil villains whose actions were 
occasionally classified by others as 'twisted', 'sick' or 'nuts'. Mental illness references had a central implication that the character was losing control. Most such references pointed either to an external stimulus or stressor ("you're starting to drive me willy") or to the illness originating in an unexplained fashion. The only exception was provided by Pinky and the Brain where, in the title sequence, viewers were shown X-rays of Pinky's attenuated brain and the Brain's engorged organ, the results of their time as laboratory subjects.

\section{Character depictions}

In the sample six characters were consistently identified as having a mental illness; three served a comic role (Go-Go, Green Fog, Pinky) and three were portrayed as evil villains (Brain, Hoit Gunterkrust, Dr Von Trapp). All six were characters in cartoon episodes. All were animated and male, only one was 'human', the others were respectively a bird-like creature, a frog, two mice and a robot. In their depictions some physical attributes were commonly emphasised. Teeth: top, bottom or both were widely spaced and in one character were rotting, producing bad breath. Other facial features included a prominent nose, heavy brows with thick, arched eye-brows, narrowed or artificial eyes (villains) or large round eyes (comic characters) and unruly hair (long and shaggy, tufted fur, thick and messy, bright orange curls). Extremities: hands and feet were large, often with particularly long fingers. All of these characters dressed up to some degree, the comic characters much more so than the villains. Examples included middle-eastern costume, top hats and suits, military and flight attendant uniforms, tennis gear, a doctor's white coat and stethoscope, wigs, strait-jacket, brightly-coloured shoes, vests and bow ties.

Behavioural attributes were somewhat better defined across this group, depending on whether the character functioned as the comic or as the villain. The comic 'insane' characters were continuously engaged in illogical and irrational actions such as hitting their head against a swinging light and laughing (Pinky), hand-cuffing the jury in court (Green Frog), hitting their head with a hammer (Go-Go) and sucking paper up through the nose (Go-Go). They acted as a source of innocent merriment for other characters. Additionally, they repeatedly interpreted word expressions literally, or in non-standard ways. For example, one (Green Frog), acting as a defence lawyer in court, saying 'I rest my case', put his briefcase on the table under a sheet. Another character (Go-Go), when asked what (food) was being served pulled out a tennis racket and served a ball. Villainous behaviour was determined and obsessive. Characters were shown with clenched fists, hunched shoulders, and shaking fists or objects in the air. These characters initiated evil ideas such as kidnapping, attempted murder and building an 'alter-earth'.

\section{DISCUSSION}

\section{Limitations}

As we have previously shown (Wilson et al, $1999 a$ ), it is difficult to convey through words alone how mental illness is depicted in the television medium when devices such as music, sound effects, lighting, intertextuality and their inter-relationships contribute. We were unable to include viewer age as a relevant variable because there was no clear demarcation of the targeted age of programmes (e.g. pre-school $v$. school age). Further, children may have different understandings of the references to mental illness presented here, and there is a possibility of bias towards over-inclusion of references, particularly negative references, by the adult raters. Increasing the size of the sample may have increased the range of depictions of mental illness and more positive themes may have become identifiable. The results are, therefore, not necessarily generalisable.

\section{Vocabulary}

Our findings demonstrate a high frequency of references to mental illness in children's television particularly during animated cartoons, with almost $50 \%$ of all of the programmes surveyed containing references. Furthermore, the vocabulary was predominantly negative with a common implication of loss of control. The frequent and casual use of fundamentally disrespectful vocabulary such as crazy, mad, nuts, twisted, wacko or looney demonstrated for children that such expressions are acceptable or even funny. These behavioural examples may contribute to children learning how to separate, alienate, or put others down by bullying, intimidation or verbal harassment.

\section{Characters}

The characters, whether comic or villainous, were stereotypically and blatantly negative and served as objects of amusement, derision or fear. This finding is consistent with an overwhelming negativity of depictions of mental illness in adult television and film media (Hyler et al, 1991; Signorielli, 1989; Wilson et al, 1999b). The generic nature of the illnesses portrayed and the lack of specificity of symptoms or diagnosis also invited the viewer to generalise from the depictions to all mentally ill individuals. We looked for, but did not find, any positive attributes to those who were consistently depicted as mentally ill, apart from being a source of amusement for other characters, or perhaps the engorged brain of Brain. Nor did we find any understanding of the suffering that mental illness involves, which may be a consequence of a distancing from human experience with animated characters.

Interestingly, although two characters were shown hitting their heads, either against a swinging light or with a hammer, there were no references to substance use or suicide within this sample. An aetiological perspective was also lacking other than occasional references to situational stressors or the limited biological model conveyed by the size of the brains of Pinky and the Brain.

\section{Future actions}

Clearly such preliminary findings deserve replication. We will also need to learn through reception studies what impact, if any, such negative televised references and depictions have on children's appreciation of mental illness. We are not aware of any studies that assess children's understandings of terminology or of character depictions in the media that are related to mental illness. As this information becomes available, priorities can become established for interventions including working with media, developing regulations or standards for production, and vetting of children's television.

\section{REFERENCES}

Aitken, P. P., Leathar, D. S., O'Hagan, F. J., et al (1987) Children's awareness of cigarette advertisements and brand imagery. British Journal of Addictions, 82, 615-622.

Brockington, I. F., Hall, P., Levings, J., et al (1993) The community's tolerance of the mentally ill. British journal of Psychiatry, 162, 93-99. 
Buckingham, D. (1991) What are words worth? Interpreting children's talk about television. Cultural Studies, 5, 228-245.

Butler, J. G. (1994) Television: Critical Methods and Application. Belmont, CA: Wadsworth.

Centerwall, B. S. (1992) Television and violence. Journal of the American Medical Association, 267, 3059-3063.

Diefenbach, D. L. (1997) The portrayal of mental illness on prime-time television. Journal of Community Psychology, 25, 289-302.

Fairclough, N. (1993) Critical discourse analysis and the marketization of public discourse: The universities. Discourse and Society, 4, 133-168.

Halliday, M. (1978) Language as a Social Semiotic. London: Edward Arnold.

Hollway, W. (1989) Subjectivity and Method in Psychology: Gender, Meaning and Science. London: Sage.

Hyler, S. E., Gabbard, G. O., Schneider, I. (199I)

Homicidal maniacs and narcissistic parasites:

stigmatization of mentally ill persons in the movies.

Hospital and Community Psychiatry, 42, 1044-1048.

Matas, M., el-Guebaly, N., Peterkin, A., et al (1985) Mental illness and the media: an assessment of attitudes and communication. Canadian journal of Psychiatry, $\mathbf{3 0}$, $12-17$

Mayer, A. \& Barry, D. D. (1992) Working with media to destigmatize mental illness. Hospital and Community Psychiatry, 43, 77-78.

McCreanor, T. N. (1997) When racism stepped ashore: antecedents of anti-Maori discourse in Aotearoa. New Zealand Journal of Psychology, 26, 36-44.

Mulkay, M. (1985) The Word and the World: Explorations in the Form of Sociological Analysis. London: George Allen \& Unwin.

Nairn, R. G. \& McCreanor, T. N. (1991) Race talk and common sense: Patterns in Pakeha discourse on Maori/ Pakeha relations in New Zealand. Journal of Language and Social Psychology, 10, 245-262.

Philo, G. (1996) The media and public belief. In Media and Mental Distress (ed. G. Philo), pp. 82-104. London: Longman.

—, Henderson, L. \& McLaughlin, G. (1993) Mass Media Representatives of Mental Health and Illness: Content Study. Glasgow Media Group: Health Education Board for Scotland.

_ , Secker, J. \& Platt, S. (1994) Impact of the mass media on public images of mental illness: media content and audience belief. Health Education Journal, $\mathbf{5 3}$ $27 \mid-281$

\section{CLINICAL IMPLICATIONS}

- There was a high frequency of references to mental illness in children's television, particularly during animated cartoons.

- The references were predominantly negative and stigmatising.

- Children are being socialised into adult prejudices against mental illness.

\section{LIMITATIONS}

- Television depictions of mental illness are constituted through the interplay of language and technical devices and are difficult to describe in words alone.

- Viewer age was not included as a relevant variable because there was no clear demarcation of the targeted age of programmes.

- In the absence of reception studies it is not possible to identify how children give meaning to these depictions.

CLAIRE WILSON, BSc, RAYMOND NAIRN, MSc, JOHN COVERDALE, FRANZCP, AROHA PANAPA, MSC Department of Psychiatry and Behavioural Science, University of Auckland, Auckland, New Zealand

Correspondence: Raymond Nairn, Department of Psychiatry and Behavioural Science, Faculty of Medicine and Health Science, University of Auckland, Private Bag 92-019, Auckland, New Zealand

(First received 17 August 1999, final revision 22 November 1999, accepted 22 November 1999)

Siegal, M. (1991) Knowing Children: Experiments in Conversation and Cognition. Hove: Lawrence Erlbaum.

Signorielli, N. (1989) The stigma of mental illness on television. Journal of Broadcasting and Electronic Media, 33, 325-331.

Wahl, O. F. (1992) Mass media images of mental illness: a review of the literature. Journal of Community Psychology 20. 343-352.

- (1995) Media Madness: Public Images of Mental Illness. New Brunswick, NJ: Rutgers University Press.

— \& Roth, R. (1982) Television images of menta illness: results of a metropolitan Washington media watch. Journal of Broadcasting, 26, 599-605.
Wilson, C., Nairn, R., Coverdale, J., et al (1999a) Constructing mental illness as dangerous: A pilot study. Australian and New Zealand Journal of Psychiatry, 33. 240-247.

_ , _ , _ , et al (1999b) Mental illness depictions in prime-time drama: Identifying the discursive resources. Australian and New Zealand journal of Psychiatry, 33, 232-239.

Wolff, G., Pathare, S., Craig, T., et al (1996)

Community attitudes to mental illness. British journal of Psychiatry, 168, 183-190. 